SLA-74-0069

Unlimited Release

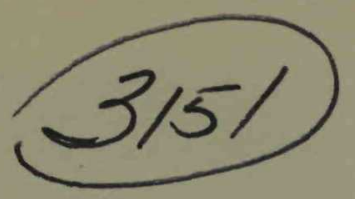

- Cecanted BY TC JUN 17 gRT

\title{
Nondestructive Testing for Mechanical Defects in ATJ-S Graphite
}

J. H. Gieske, B. L. Butler, T. R. Guess,

J. M. Freedman, R. H. Marion

Prepared by Sandia Laboratories, Albuquerque, New Mexico 87115

and Livermore, California 94550 for the United States Atomic Energy

Commission under Contract AT $(29-1)-789$

Printed May 1974

\section{Sandia Laboratories}


Issued by Sandia Laboratories, operated for the United States Atomic Energy Commission by Sandia Corporation.

\section{NOTICE}

This report was prepared as an account of work sponsored by the United States Government. Neither the United States nor the United States Atomic Energy Commission, nor any of their employees, nor any of their contractors, subcontractors, or their employees, makes any warranty, express or implied, or assumes any legal liability or responsibility for the accuracy, completeness or usefulness of any information, apparatus, product or process disclosed, or represents that its use would not infringe privately owned rights.

SF $1004-D F(2-74)$ 


\section{DISCLAIMER}

This report was prepared as an account of work sponsored by an agency of the United States Government. Neither the United States Government nor any agency Thereof, nor any of their employees, makes any warranty, express or implied, or assumes any legal liability or responsibility for the accuracy, completeness, or usefulness of any information, apparatus, product, or process disclosed, or represents that its use would not infringe privately owned rights. Reference herein to any specific commercial product, process, or service by trade name, trademark, manufacturer, or otherwise does not necessarily constitute or imply its endorsement, recommendation, or favoring by the United States Government or any agency thereof. The views and opinions of authors expressed herein do not necessarily state or reflect those of the United States Government or any agency thereof. 


\section{DISCLAIMER}

Portions of this document may be illegible in electronic image products. Images are produced from the best available original document. 
SLA - 74-0069

Unlimited Release

NONDESTRUCTIVE TESTING FOR MECHANICAL

DEFECTS IN ATJ-S GRAPHITE

J. H. Gieske, 9352

B. L. Butler, 5843

T. R. Guess, 5847

J. M. Freedman, 1542

R. H. Marion, 5847

Sandia Laboratories, Albuquerque, New Mexico 87115

Printed May 1974

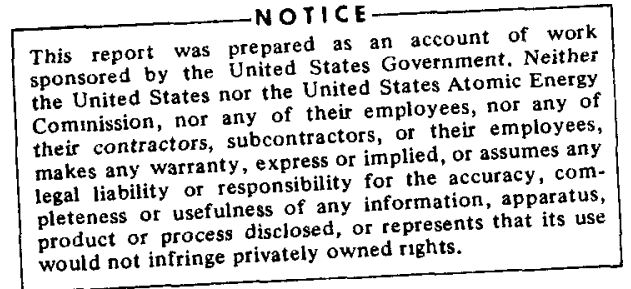

ABSTRACT

The correlations between the results of both NDT ultrasonic pulse echo and radiation-gaging (DXT) techniques of flaw detection and the degradation of mechanical properties and density of ATJ -S graphite are presented. Control specimens containing few or no detectable flaws were of uniform density and had an average tensile strength of about $5000 \mathrm{psi}$; the specimens containing detectable flaws had substantial density variations and an average tensile strength of about 3400 psi. The location of ultimate fracture coincided with the location that had given the maximum NDT indication in five of the six flawed specimens.

Key words: NDT correlation, materials properties 


\section{ACKNOWLEDGMENT}

The authors, the NDT Correlation Committee, acknowledge the experimental assistance of D. E. Bishop and R. F. Soutar in the pulse echo data acquisition and DXT measurements. Also C. B. Haizlip and J. C. Tidmore for destructive testing and sample coordination. 


\section{CONTENTS}

Introduction

Test Techniques

Ultrasonic Pulse Echo

DXT Density Profile

Page

Mechanical Tests

Results and Discussion

11

Conclusions

13

References 
○

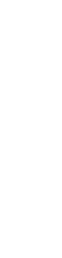




\title{
NONDESTRUCTIVE TESTING FOR MECHANICAL DEFECTS IN ATJ-S GRAPHITE
}

\author{
Introduction
}

Nondestructive test (NDT) techniques have been used at Sandia Laboratories to establish a logical method of selecting the portion of a graphite billet from which to machine a nosetip. 1 Locations of material discontinuities were pinpointed using the ultrasonic pulse echo technique. This technique has an advantage over other NDT methods for thick materials since it can be used easily to locate the depth of discrete material discontinuities. Radiography techniques are all poorer in this respect since they give only the integrated result through the full thickness of the specimen. Therefore, the material discontinuity can only be identified as an area in the plane of the $x$-ray film or in the plane perpendicular to the $x$-ray beam (DXT technique), and no depth information is possible except through a series of radiographs or DXT scans from different angles. On the other hand, for thin material specimens the ultrasonic pulse echo technique is less applicable and radiography becomes most useful.

Other investigators have found little direct correlation between the NDT results and possible degradation of mechanical properties in the regions of material discontinuities and density variations. $^{2,3}$ In this report we describe the preliminary results of a program aimed at establishing a direct correlation between NDT-detected variations and the tensile mechanical properties of ATJ -S graphite. * The results of this program will be applied to the program involving IP (Isostatically Pressed Chopped carbon fibers in a pyrolized organic matrix) and other graphitic materials.

The steps taken, in order, were (1) to cut a 3/4-inch-thick slab of ATJ-S graphite from a 6-inch diameter, cored billet (Union Carbide No, 7-E2-1), as in Figure 1a, (2) to map material discontinuities within the slab using the pulse-echo method, (3) to section the slab such that individual sections would contain either very few or very many material discontinuities, (4) to map the material discontinuities within the sectioned pieces to see if they agreed with the flaws indicated by the scan of the entire slab, (5) to machine tensile specimens which were then scanned axially using the DXT technique for locating density variations, (6) to perform tensile tests in which the initial modulus, ultimate strength, and ultimate strain were obtained, and (7) to determine the correlation between the NDT indications of material flaws or variations and the mechanical properties of tensile specimens.

WUion Carbide Product 


\section{Ultrasonic Pulse Echo}

Ultrasonic-pulse-echo data were taken over the entire slab with the use of a minicomputer-based acquisition and display system. 1

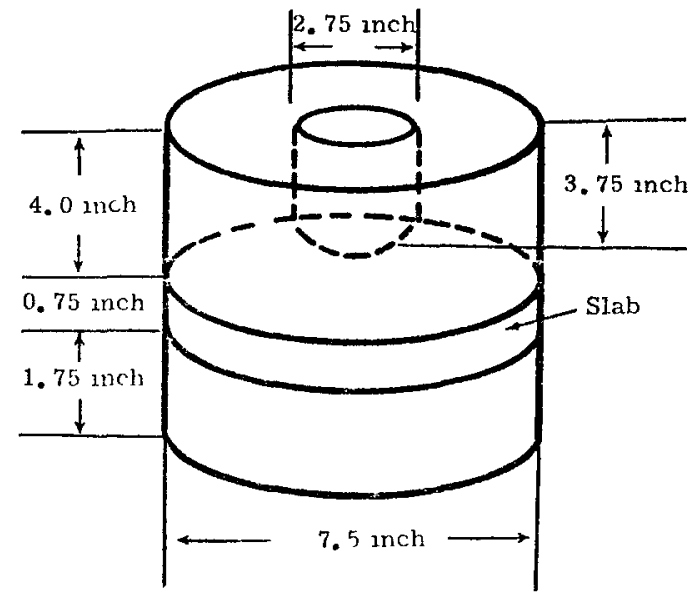

(a)

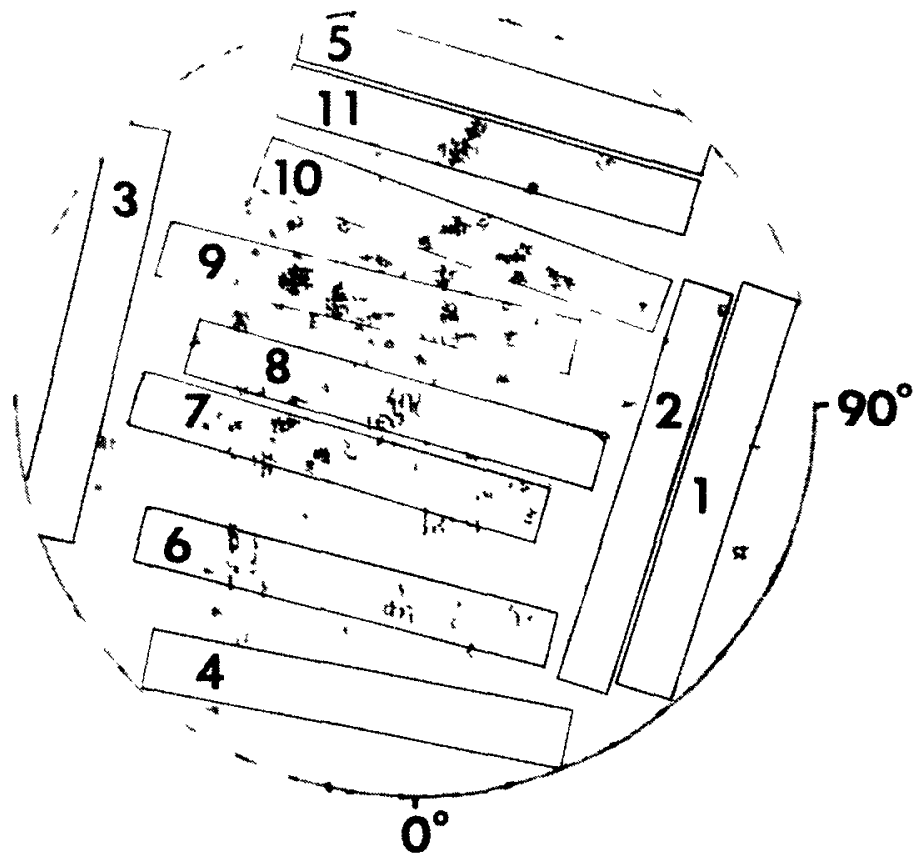

(b)

Figure 1. (a) Sketch of ATJ-S billet No, 7-E2-1 and location of slab, (b) ultrasonic pulse echo map showing black-spot indications of material discontinuities at depths between 0.18 and 0.56 inch from the top surface. Also shown in the location of the eleven blanks from which tensile specimens were machined. 
The slab was coated with a thin film of strippable PVC plastic to keep the graphite dry during the ultrasonic water-immersion test. A flat transducer of 1/2-inch diameter was used for sending and receiving the $3.5 \mathrm{MHz}$ pulses. A Velonex Model 570 high-voltage pulser and appropriate in-house ultrasonic receiver apparatus were used to provide the computer with analog voltages, which were a measure of the amplitude of each received echo along with a voltage proportional to the time delay of a given echo with respect to the time delay of the front-surface echo. The gain of the receiver was adjusted to give a linear, time-corrected gain over the full thickness of the slab in order to compensate for the attenuation of the ultrasonic pulse as it travels through twice the thickness of the slab. This was done so an echo amplitude from a material discontinuity near the back surface of the slab would be equal in height to an echo amplitude from an identical material discontinuity near the front surface. The gain was adjusted arbitrarily until an even distribution of echoes was obtained through the full thickness of the slab and a fair number of them occurred at about 50\% amplitude height with respect to a arbitrary $100 \%$ maximum amplitude which is the set limit for the receiver/computer interface.

Figure $1 \mathrm{~b}$ is a top view of the slab showing the pulse-echo data obtained. The slab was scanned in a raster fashion over its entire area. Each dark dot represents an echo received from a material discontinuity between 0.18 and 0.56 inch deep within its thickness. Only echoes with an amplitude greater than $45 \%$ are displayed.

From the measured time delay of the back-surface echo, the depth in the slab from which a given echo originates can be ascertained. Using the mini-computer display unit, those echoes which originate from certain preselected depths can be displayed individually. This allows one to cut tensile specimens at the depth from which a significant number of high-amplitude echoes either were recorded or were not recorded.

With these considerations in mind the slab was cut into 11 pieces, each 4 inches long by $1 / 2$-inch wide, from which tensile specimens could be machined, Figure $1 \mathrm{~b}$ shows the outline of these 11, where 5 pieces were chosen so the gage section of the tensile specimens would contain an area in which no significant echoes were obtained. The other 6 were chosen so the tensile specimens would contain areas of numerous material discontinuities as indicated by the pulse-echo data.

After the 11 pieces were cut from the slab and marked on the ends, a second ultrasonic test was performed on each piece to compare them with one another and with the pulse-echo data of the original slab. Figure 2a shows the pulse-echo display of the data of the cut pieces where the dots represent echoes whose amplitude was greater than $45 \%$ and originated from between the depths of 0.18 and 0.56 inch. For comparison a copy of Figure $1 \mathrm{~b}$ was taken and the 11 specimens were cut out with scissors and arranged in numerical order, as shown in Figure 2b. This provides a check on the pulse-echo results from the slab and the individual pieces. Almost a one-to-one correspondence occurs for each of the 11 pieces which verifies that the pulse-echo data is indeed repeatable, indicating that the lateral free surfaces of the blanks did not affect the ability to detect flaws in ATJ $-\mathrm{S}$. 


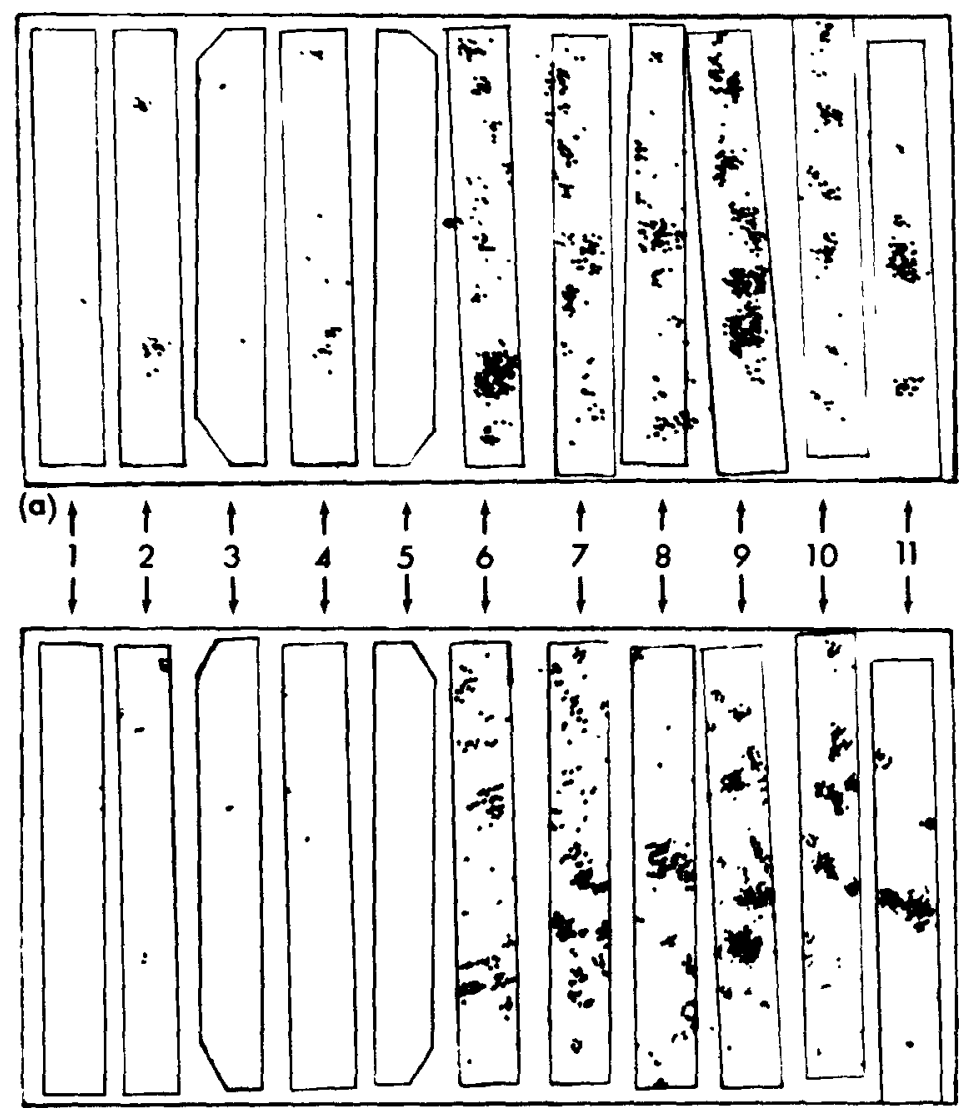

(b)

Figure 2. (a) Pulse-echo traces of actual specimen blanks sawed from the slab according to Figure $1 \mathrm{~b}$, (b) specimen pulse echo traces cut and pasted from Figure $1 b$.

\section{DXT Density Profile}

The machined tensile specimens, having the dimensions shown in Figure 3, were inspected through the diameter of the gage section with a collimated $x$-ray beam of approximately 60 mils diameter to check for density variations within the gage section. (The specimens were machined from the center of the specimen blanks). Four DXT traces throughout the gage section were obtained for each specimen, one each at $0,45,90$, and 135 degrees rotation. The four traces were made to provide sufficient coverage of the gage section and prevent a density variation near the outside surface of the specimen from affecting the results too much, as might be the case with only one trace. A calibrated lucite step-wedge was also scanned with each trace so that absolute density differences could be measured for each trace. The relative density data were placed on an absolute scale by independently measuring the bulk density of the material within the gage section of specimen 1 (using mercury displacement and weight/volume techniques) to be $1.84 \mathrm{~g} / \mathrm{cm}^{3}$. The DXT density results are listed in Table I. These results are significant to $\pm .01 \mathrm{~g} / \mathrm{cm}^{3}$. 


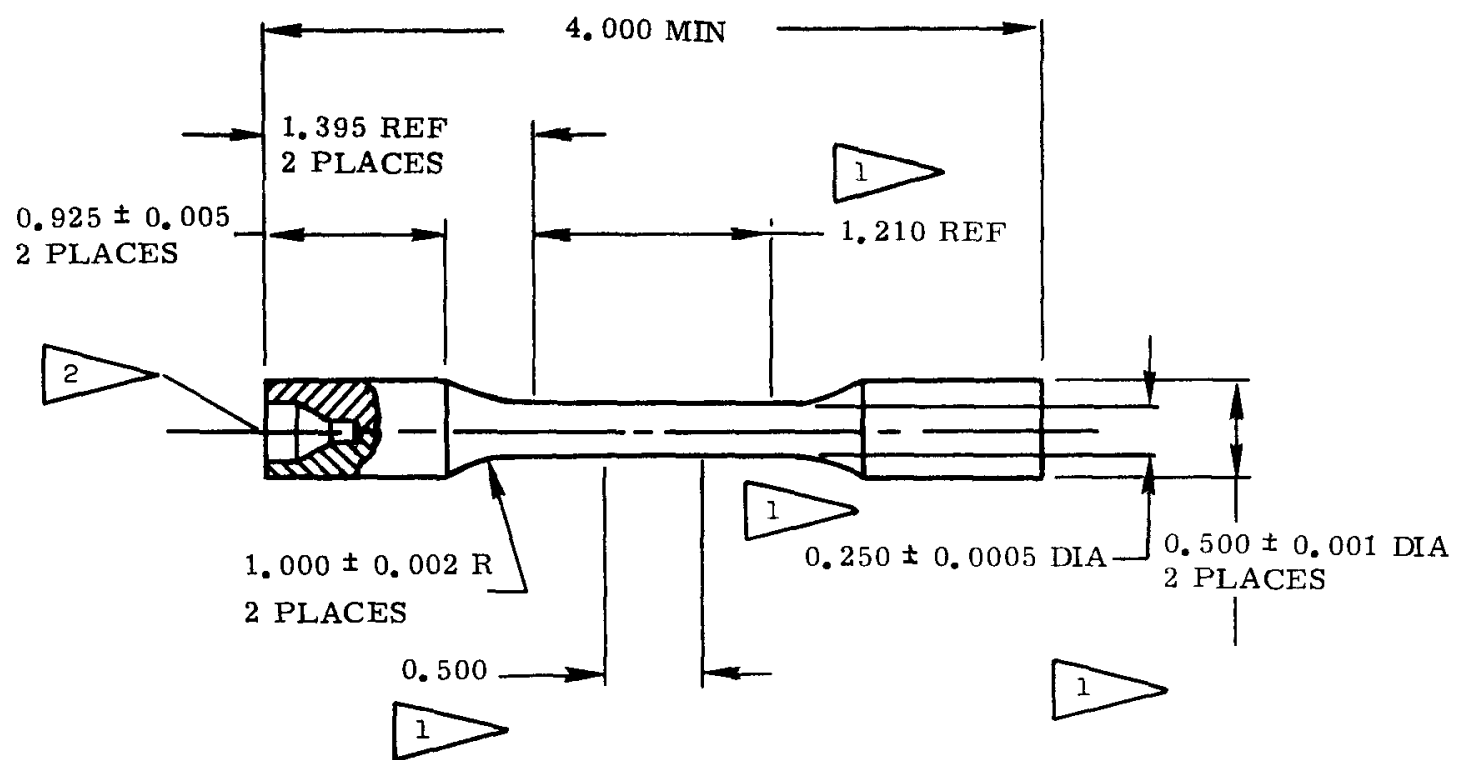

1. Diameter of the 1.210 section shall be uniform within $0.250 \pm 0.0005$ with no undercut at the radius blend. The minimum diameter shall fall within the 0.500 center section and must be smaller by 0.0001 to 0.0002 than the other parts of the 0.250 diameter; no sharp change in diameter permitted. The two 0.500 diameter sections shall be concentric within 0.001 T.I. R. of the 0.250 diameter.

2. Centering drills and/or countersinks permissible to maximum depth of $0.500,2$ places, and shall be coaxial with 0.001 T.I. R.

Figure 3. Specification for machining ATJ-S tensile specimens Dimensions are in inches.

Mechanical Tests

Tensile testing was performed on each of the specimens using an Instron Model TTCML

screwdriven test machine. The specimens were held with wedge-locking grips, the strain measurements were monitored by a 1 inch gage length clip-on extensometer, and the tests were conducted at a cross-head deflection rate of $0.008 \mathrm{in}$. $/ \mathrm{min}$. A typical stress/strain curve is shown in Figure 4. The responses were similar for all specimens, each being approximately linear at low stress levels, then becoming nonlinear to failure. The tangent modulus was determined from the initial region of the stress/strain curve. The initial tanget modulus, maximum strength, and ultimate strain data are listed in Table I. 
TABLE I

Summary of Pulse Echo, DXT, and Physical Properties of the ATJ-S Graphite Specimens

\begin{tabular}{|c|c|c|c|c|c|c|c|}
\hline Specimen & $\begin{array}{l}\text { Pulse Echo Data } \\
\text { of Gage Section }\end{array}$ & DXT & $\frac{\text { Density }}{\text { Max. }}$ & $\frac{\left(\mathrm{g} / \mathrm{cm}^{3}\right)}{\text { Min. }}$ & $\begin{array}{c}\text { Tensile } \\
\text { Strength } \\
\text { (psi) }\end{array}$ & $\begin{array}{c}\text { Initial Young's } \\
\text { Modulus }\end{array}$ & $\begin{array}{l}\text { Strain to } \\
\text { Failure } \\
(\%)\end{array}$ \\
\hline 1 & No Echoes & 1.84 & 1.85 & 1.83 & 4991 & 1.37 & 0.50 \\
\hline 2 & Two Echoes & 1.83 & 1.84 & 1.83 & 4761 & 1.35 & 0.50 \\
\hline 3 & No Echoes & 1.84 & 1.85 & 1.84 & 5320 & 1.61 & 0.44 \\
\hline 4 & No Echoes & 1.85 & 1.86 & 1.84 & 5050 & 1.45 & 0.50 \\
\hline \multirow[t]{3}{*}{5} & No Echoes & 1.85 & 1.85 & 1.84 & 5150 & 1.51 & 0.42 \\
\hline & Average & 1.842 & 1.850 & 1.836 & 5054 & 1.46 & 0.47 \\
\hline & Std. Dev. & 0.008 & 0.007 & 0.005 & 206 & 0.10 & 0.04 \\
\hline 6 & 3 Clusters of Echoes & 1.81 & 1.82 & 1.77 & 3460 & 1.51 & 0.31 \\
\hline 7 & 4 Clusters of Echoes & 1.81 & 1.82 & 1.79 & 3650 & 1.30 & 0.39 \\
\hline 8 & $1 \mathrm{Lg}$. Cluster of Echoes & 1.80 & 1.82 & 1.72 & 3100 & 1.31 & 0.34 \\
\hline 9 & $4 \mathrm{Lg}$. Clusters of Echoes & 1.80 & 1.81 & 1.79 & 3000 & 1.35 & 0.31 \\
\hline 10 & $1 \mathrm{Lg}$. Cluster of Echoes & 1.81 & 1.83 & 1. 79 & 3100 & 1.33 & 0.30 \\
\hline \multirow[t]{3}{*}{11} & $1 \mathrm{Lg}$. Cluster of Echoes & 1.83 & 1.85 & 1.82 & 3950 & 1.37 & 0.39 \\
\hline & Group 2 & 1.810 & 1.825 & 1.780 & 3386 & 1.36 & 0.34 \\
\hline & Std. Dev. & 0.010 & 0.014 & 0.033 & 375 & 0.08 & 0.04 \\
\hline
\end{tabular}

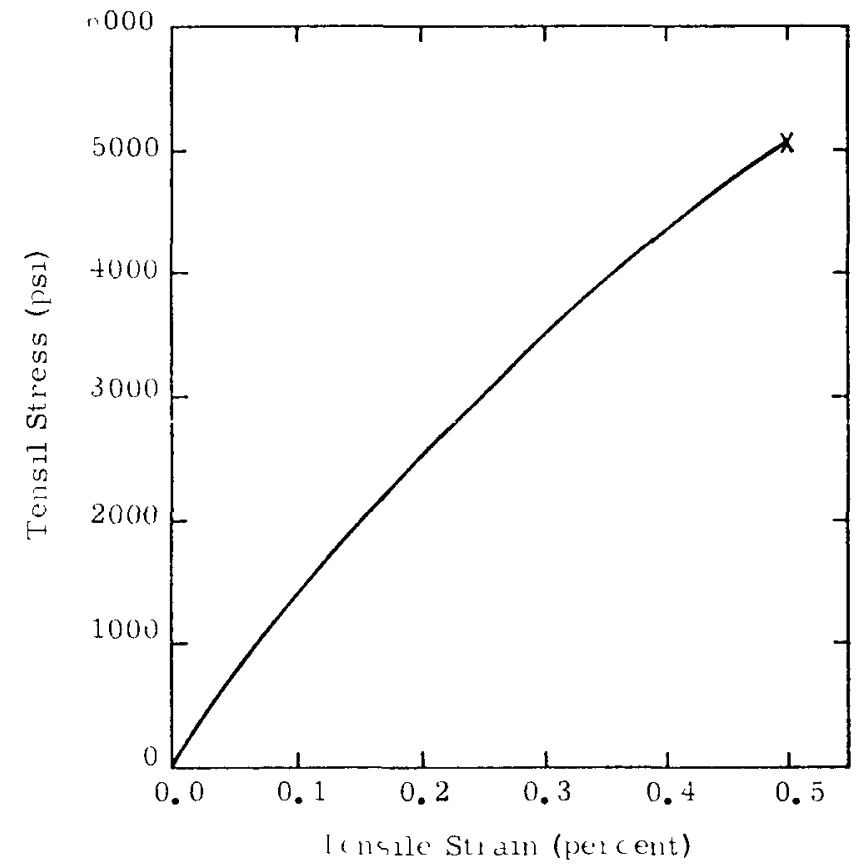

Figure 4. Stress/strain response of specimen 4 
Results and Discussion

The ultrasonic-pulse-echo data indicating material discontinuities, the $\mathrm{x}$-ray DXT data indicating density variation, and the mechanical properties data for each specimen are listed in Table I. The specimens are grouped according to the absence or presence of significant numbers of high-amplitude ultrasonic pulse echoes. It is assumed that Group 1 specimens (very few pulse echoes recorded) are essentially free of flaws or material discontinuities and can be considered control specimens, i. e., representative of the unflawed material. Comparison of the Group 1 and Group 2 properties clearly demonstrates the degradation in the properties of the specimens having a large number of material discontinuities. The strength and ultimate strain are significantly lower in the Group 2 specimens than in the control specimens. In addition, the density and modulus of the Group 2 specimens, which were all selected from near the middle of the billet, are slightly lower in value than for the Group 1 specimens--all taken from outside billet material. (This result is also indicated from the pulse-echo data which shows that the area of numerous material discontinuities is around the center of the billet, thus implying material of lower density.)

It is of interest, also, to compare the exact location of fracture with the location of both the pulse-echo records and the density variations within the gage section. A schematic of these parameters is shown in Figure 5. Note that within the gage section of the Group 1 specimens (essentially free of flaws by the pulse-echo technique) the density variations are minimal. This observation is in direct agreement with the pulse-echo data. There are more pronounced density variations in the Group 2 specimens. In some cases (specimens 6, 7, 8, 9, and 11) there appears to be a direct correlation between fracture location and position of lowest density. The notable exception is specimen 10. However, in that specimen the fracture occurred at the point of maximum number of pulse echoes.

A precise description of the relation between fracture location and NDT mapping is not possible at this time. The ultrasonic and $\mathrm{x}$-ray scanning methods cannot distinguish between the sizes, geometries, distributions, and relative positions of the voids. Thus it may be possible for a single large void not to be detectable by the DXT test from an equal distribution of very small voids or pores. This large flaw could possibly cause failure as might be the case in specimen 10 . Likewise, a large array of small pores, causing a low density region, may not be detectable with the pulse echo technique. Thus fracture may occur in this region, as might have been the situation in specimen 9 , even though it wouldn't be predicted from the ultrasonic data.

The correlation between NDT-detected flaws and property degradation is obvious and a correspondence between the location of fracture and location of maximum flaws by ultrasonic pulses and/or location of minimum density by the DXT method was found in all six flawed specimens. Thus these preliminary results are very encouraging and the program is being actively continued. Future work will include fractography of failure surfaces. 

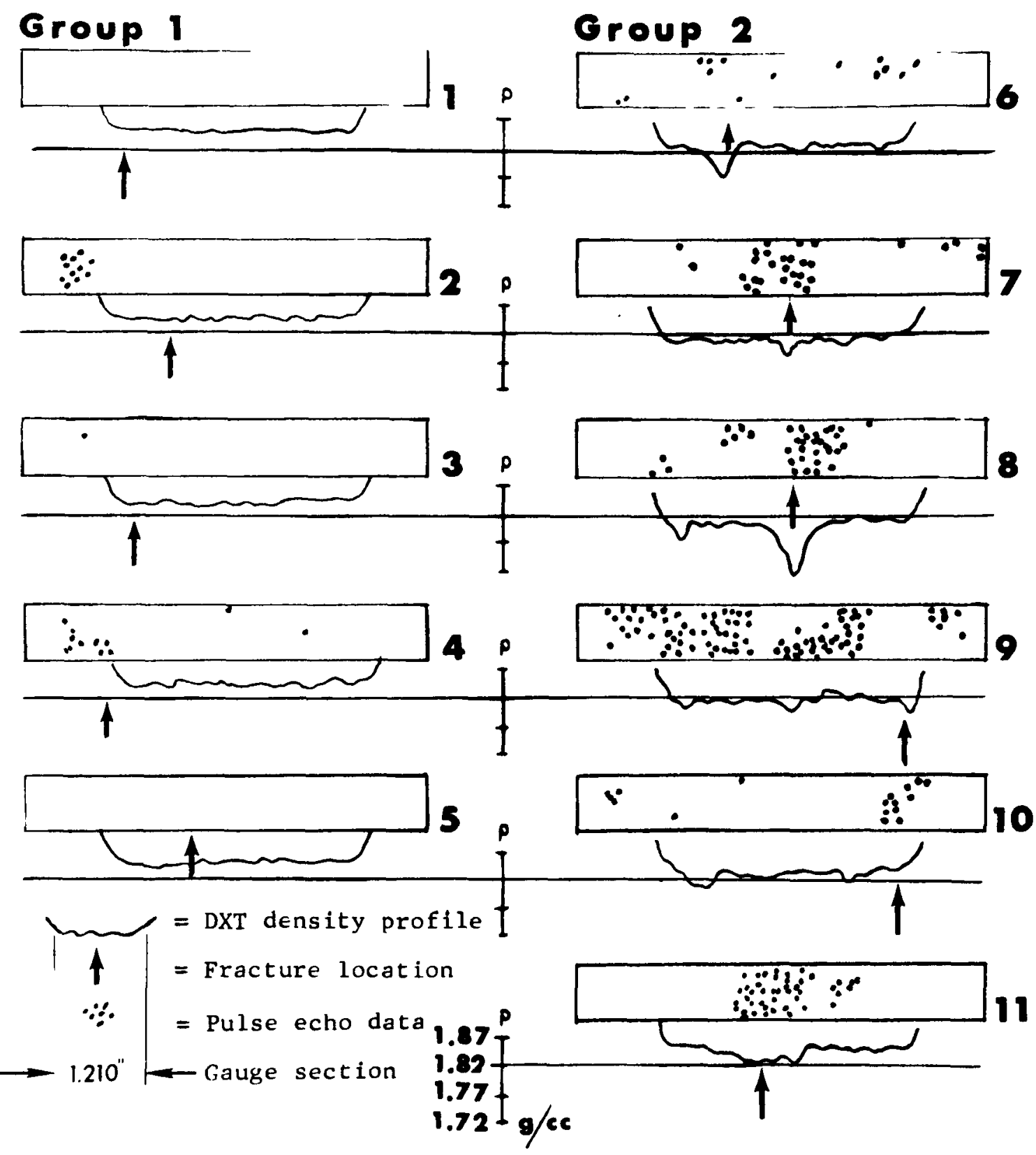

Figure 5. Pulse-echo data and DXT density profiles of gage sections at ATJ-S tensile specimens. The strips shown represent the 0.25 inch gage section diameter and only those echoes lying at a depth which falls within the gage section are shown. Arrows show failure locations. 


\section{Conclusions}

1. Degradation of mechanical properties (strength, modulus, and ultimate strain) and density have been correlated to internal flaws in ATJ-S graphite. The flaw locations were mapped using the NDT ultrasonic-pulse-echo technique.

2. In most cases, the detectable flaws appear to be related to regions of low density (high porosity) which were determined by the $\mathrm{x}$-ray DXT method.

3. The location of fracture generally coincided with a region of maximum flaws (by pulse echo method) and/or the region of lowest density (by DXT method). Both pulse echo and DXT techniques are valuable in characterizing flaws;

4. pulse-echo data are more useful for thick pieces and DXT data are more useful for machined or thin pieces. 


\section{References}

1. R. A. Baker, D. E. Bishop, and G. C. Stoker, "Ultrasonic Characterization and Computerized Analysis of Graphite Billets, " Sandia Laboratories Report SC -DR $-70-693,1970$.

2. W. L. Shelton and G. R. Atkins, "The Correlation of Nondestructive Test Techniques with the Fracture Behavior of ATJ-S Graphite," AFML-RT-72-38, August 1973. Distributed by NTIS \#AD-751-976.

3. R. A. Youshaw, D. Polansky, and E. L. Criscuolo, "Nondestructive Testing of Graphite for the Revmat Program Office, " Naval Ordnance Laboratory Report NOLTR $73-118$, July 1973. 
DISTRIBUTION :

Mason \& Hanger

Silas Mason Co., Inc.

AEC Pantex Plant

P.O. Box 647

Amarillo, Texas 80105

Attn: D. L.Dufek (1)

Lawrence Radiation Laboratory

P.O. Box $30 \mathrm{~s}$

Livermore, California 94551

Attn: R. G. Liptal (1)

Support Division L-415

WADCO

P.O. Box 1970, 300 Area

Attn: H. N. Pedersen (1)

D. R. Green (1)

Oak Ridge National Laboratory

P.O. Box X

Oak Ridge, Tennessee 37430

Attn: R. W. McClung (1) Metals \& Ceramics Div. NDT Technology

Los Alamos Scientific Laboratory P.O. Box 1663

Los Alamos, New Mexico 27544

Attn: D. E. Elliott (1)

GMX - 1

Union Carbide Corporation (6)

Y - 12 Plant

P.O. Box Y

Oak Ridge, Tennessee 37830

Attn: L. E. Burkhart

V. C. Jackson

D. L. Mason

A. J. Taylor

C. B. Pollock

J. M. Napier

Battelle Memorial Institute 505 King Avenue

Columbus, Ohio 43201

Attn: D. N. Treweek (1)

E. L. Foster (1)

U. S. Naval Ordnance Laboratory (3)

White Oak

Silver Spring, Maryland

Attn: E. L. Criscuolo

F. Koubek

Leo Gowen

Lockheed Missiles \& Space Co.

Dept. $81-22$

P.O. Box 504

Sunnyvale, California 94088

Aitn: V. P. Mamone
Dr. M. Sinnott

Director of Material Science, ARPA

1400 Wilson Blva.

Arlington, Virginia 22209

Jerome Persh

Office of Director of Defense

Research and Engineering

Pentagon - Room 3F - 1071

Washington, D. C. 20301

Marlin A. Kinna

Materials Research Engineer

ORD-0331

Naval Ordnance Systems Command

Washington, D. C. 20360

Don Schmidt

Air Force Materials Laboratory

Wright-Patterson AFB, Ohio 45433

SAMSO (2)

P.O. Box 92960

Worldway Postal Center

Los Angeles, California 90009

Attn: G. M. Hess

Capt. James Green

Capt. John Gordon

AFWL/DYV

Kirtland AFB, New Mexico 87116

Prototype Development Associates (2)

Esplanade 1, Suite 204

3001 Red Hill Avenue

Costa Mesa, California 92626

Major Gen. Frank A. Camm

Asst. Gen. Mgr. for Military Apple(a'cr) in Attn: Col. William B. Haidler

Asst. Dir. Res, and Dev, with D $\backslash 41$

U.S. Atomic Energy Commission

Washington, D. C. 20545

John Dignam

Department of the Army

Army Mater'1als and Mechanics

Research Center

Watertown, Massachusetts 02172

George Strouhal

National Aeronautics and Space Aiti in. Manned Spacecraft Center

Houston, Texas 77058

LCDR L. Stoessl, SP272 (3)

Strateglc Sistem Projects

Drpar tment of the \aw

Washington, D. C. $203^{r}()$ 
inn it. Swartz

Defense Nuclear Agency

Waulington, D. C. 20305

C. D). Fors (2)

Southern liesearch Institute

200 Ninth Avenue South

Birmingham, Alabama 35205

T. B. Lane, 1540

T. G. Priddy, 1542

J. Freedman, 1542 (10)

T. B. Lane, Actg., 1543

W. N. Sullivan, 1543

J. T. Schamaun, 1544

A. Narath, 5000

Attn: A. Narath, Actg., 5100

E. H. Beckner, 5200

A. Y. Pope, 5600

J. W. Scott, 5700

$\therefore$ MlcAlees, Jr., 5628

1. Autrbach, 5628

(r. F. Wright, 5628

R. F. Sheldahl, 5628

I. W. Schmitt, 5723

1). I. Rigali, 5725

. I. Iruin, 5725

M. ih. Sterk, 5725

L. M. Berry, 5800

w1. R. (. Kulle, j811)

R. L. Schwoebel, 5820

M. J. Davis, 5830

R. C. Heckman, 3823

R. l. Acton, 5823

R. C. Lincoln, 5823

1. W. Mullendere, , $82:$

L. M. Berre, Acts., 5340

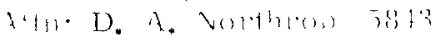

1). He orellan, , : $: t$

F. K. Beatuchamp, jotb

13 [.. Butler, $584 ?$ (10)

‥ N. Cur ]ee, 5843 $11: \quad \because 3: 3$

W. hatnes, 5847

T. R. Guess, $5847(10)$

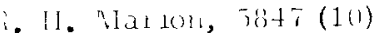

L. F. Voolker, 8113

; A. Veilaon, 0370

3. U. Buldaid, 43.j1

1\%, (x. Sample, 93,51

R. r. Solutal, 9351

0. J. Burchett, 9352

1. 1. B14hup, 93.52

J. (. Bushnet1, 9.3.32

I. II. Ciriske, $9352(20)$

1. - a 14.9332

isusion it 1 (i)

Diva-1, $0326,(2)$

1) HVLat.313151 (3)

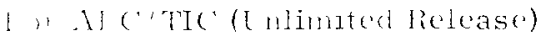

